\title{
PICO AND FEMTO CELLS DISTRIBUTION EFFECT ON USER ASSOCIATION PERFORMANCE IN 5G HETEROGENEOUS NETWORKS
}

\author{
Yahia S. Mohameda, Aziza I. Hussein ${ }^{b}$, Ahmed Zakariac \\ ${ }^{a}$ Electrical Engineering Department, Faculty of Engineering, El-Minia University, Egypt \\ ${ }^{b}$ Electrical \& Computer Engineering Department, Effat University, Jeddah, KSA \\ ${ }^{c}$ Telecommunication Engineer, Telecom Egypt, Asyut, Egypt
}

\section{ABSTRACT}

5G Heterogeneous Networks (HetNet) deployment of low-power with low-cost Small Base Station (SBSs) such as Picocell and Femtocell BS (PBS and FBS) establish a precious solution for improving the musty Macrocell BS (MBS) capacity, reliability, and coverage, etc. This paper studies the effect of SBS distribution on the overall performance of the cellular network. The homogeneous Poisson Point Process (HPPP), Poisson Cluster Processes (PCP), and Matern Cluster Processes (MCP) are considered as distribution models used for this study. The cell association algorithm that is being used in this research is Cell Based Association algorithm (CBA), which is based on Nash Bargaining Solution (NBS). The challenges addressed in this paper feature the work of cell association in heterogeneous networks in three tiers with the perspective of newly emerging WiGig technology. Another challenge addressed in this paper is the consideration of the user distribution method. This paper assumes the user is distributed based on non-uniform user distribution model in which the user density depends on the distance to the associated base stations (BSs). The MCP distribution model achieve optimality (14\% \& 8\% increase in total System Data Rate (SDR) and total Jain's fairness index (JFI) respectively comparison to the HPPP and PCP. The MCP distribution model has the advantage of taking the dependence between Macro and small base stations into consideration. Another advantage of MCP is that the data rate depends on the density of spatial area and is very closely affected by it, as is the case in PCP, while this property is not considered by the PPP distribution model.

Keywords: 5G, HetNet, Poisson Point Process, Poisson Cluster Processes, Matern Cluster Processes, Cell association.

\section{INTRODUCTION}

Data usage by smartphones continues to increase in all countries of the world as there are significant differences in the forms of data use between wireless cellular networks, mobile markets and user sectors. For now, wireless HetNet (Heterogeneous Network) faces excitable data traffics demands, mainly video streaming, IoT (Internet of Things), gaming, and AR/VR (Augmented Reality/Virtual Reality, etc.). Also, there are several elements that lead to higher data usage such as growth in the total users of mobiles, high performance of the mobile sets, and extra alluring data plans that increase the intensive contents of data. All these needs push us to look for other complementary alternatives to facilitate the high pressure of MBSs. It is not just a single technology of mobile networks that is prepared to deal with expansion in data traffic, aggregation between many network technologies radio is a priority. For this purpose, the network obtains additional mobile users while being aware of the needed data traffic. Network operators started reaping the benefits of multiple overlapped modern network radio access techniques, like WiMAX, UMTS, wireless LAN, Advanced LTE, and 5G.

HetNet deploys many types of base stations which differ in terms of max transition power, converge area size Received:1 March, 2021, Accepted:13 May, 2020
, deployment ease and frequency band, etc. [1]. Usage

of multiclass and multiband stations not only recover the MBSs loopholes of coverage but also move the overload traffic into different low power small BSs. This operation, called cellular network offloading, occurs for relaxing the MBSs' service stress resulting from the huge increase in user requests for traffic. Also, in HetNet, the user association has a very important role in network data offloading, improving the spectrum efficiency, energy efficiency, and load balancing of networks [2], [3] and [4].

The association of UE to the best BS is the procedure that assigns the user to one of different base stations available in the network. Commonly, user association's traditional basics is to enable a user association with only one BS at a time. Although, it has been notified the decision choice for user connection to one BS is the main factor that achieves the user data rate. In the literature, many research studies have centered on the performance metrics. The network performance that is under study such as signal to interference noise ratio distribution, the coverage, the outage probability, and data rate in cellular network are used in the traditional user methods in stochastic geometry listed in [5-13].

Many appropriate differences occur via these listed models, but all of them presume that the positions of base stations are dependent on a homogeneous Poisson Point Process (HPPP) for both of the single/multiple tier 


\section{Vol.42, No.1. January2023}

heterogeneous mobile networks. Analytical approaches invoking stochastic geometry and treat the base stations location as HPPP have garnered popularity. These approaches pick up the random topological in geometry of the network, leading to well-established mathematic tools, and permit high flexible analysis with accurate results as for the traditional grid network model. Furthermore, the HPPP distribution is operating properly when the cells are distributed in uniform manner spaces, like ad-hoc wireless networks or sensor networks. For example, in [13], the authors theoretically assume biased cell association in a multiple tier HetNet in which the Base Stations are distributed spatially as a homogeneous Poisson Point Process.

In practice, human activities are not completely random nor exhibits to be clustered around densely populated cities. So, the Poisson Point Process (PPP) assumption does not give the accurate model of interference in that environment. Although the presumption of PPP leads the analysis to be manageable, it does not look real in the case of non-uniformed distributed UEs. Besides this, the operators tend to use the small BS where many people aggregate (with the purpose to depressurize Macro BS), it is expected that the positions of Small BSs are spread in a clustered distribution. Furthermore, almost all research states that the UEs are located in a uniform distribution all over the region. Consequently, these studies don't take dependence between UEs and the Base Stations into consideration. Also, the macro/small BS dependence and the BSs/UEs dependence has not been discussed in detail.

This encourages the authors to find preferable methods to describe the HetNets aggregate interference when the transmission Base Stations are clustered. Here we suggest a 3-tier Heterogeneous Network in which the Base Stations are distributed randomly dependent on a PCP distribution based on [14], and Matern cluster processes (MCP) as [16]. In [14]-[15] the authors propose a downlink multiple tier heterogeneous cellular network with random distributed cells dependent on a Poisson cluster process. The BSs may vary in terms of transmitted power, density of cells, and reliability of the UE/BS link. Also, this BS differs in the bias towards admitting mobile users. Another distribution model considered in this paper is the MCP method [16]-[17]. PCP results from a nondependent homogeneous clustering method applied to a homogeneously Poisson process. In PCP, a homogeneous Poisson process is formed from the parent points. The representative cluster daughter points are random in number and are independently dispersed with homogeneous spatial probability density round the original point. In [25], the author develops an analytical framework for the evaluation of the analytical tools to characterize the performance metrics for typical user in a K-tier HetNet where the BS locations of each tier follow either a Poisson point process (PPP) or a PCP. In [26], the authors develop a new approach to model and analyses heterogeneous cellular networks (HetNets) that accurately incorporate coupling across the locations of users and base stations, which exists due to the deployment of small cell base stations (SBSs) at the places of high user density. The authors in [27] present an improved algorithm for small cell (SCs) deployment based on joint optimization of load balancing and interference minimization over the number and locations of the distributed user equipment (UE) forming a hotspot (HS).

The cell association algorithm that is being used in this research is Cell Based Association algorithm (CBA), which is based on Nash Bargaining Solution. This algorithm establishes a rank table for each UE based on the link capacity between all BS and all UE. Then the algorithm specifies the best BS that will achieve the highest utility of UE based the Nash Bargaining Solutions (NBS). This paper deals with cell association in heterogeneous networks in three tiers with the perspective of newly emerging WiGig technology. Another challenge addressed in this research is the consideration of the user distribution method. This paper assumes the user is distributed based on non-uniform user distribution model in which the user density depends on the distance to the associated base stations (BSs).

The content of this paper is summarized as follows:

- Section 2 shows, in detail, the cellular network architecture used in this paper;

- Section 3 depicts the three distribution models for small cells locations;

- Section 4 lists the association system used for finding the best cell that each user should be associated with;

- Section 5 provides a detailed review of the results of the experiments; and

- Section 6 outlines the conclusion.

\section{THE CELLULAR NETWORK ARCHITECTURE}

$5 \mathrm{G}$ cells compose a straight and effective process to increase the capacity of the network. 5G cells rely on dense reuse of the spectrum among the geographical network area and as a result, it brings Base Stations next to UEs. 5G HetNet is composed of different tiers. 5G New Radio (NR) MBS, which will be the first tier, is directly connected to the main core network through a fiber link. The SBS cells, which consist of many types of small power, less complex BS, overlay the existing Macrocell network. $5 \mathrm{G}$ is practically composed from multi-tier HetNet rollout, which involve small station underlying macro stations cellular networks. Small stations, like Picocells and Femtocells transmit with relatively small power and work as the essential element to offload the traffic from Macrocell. As a result, refining the overall quality of coverage and enhancing the performance of UEs 


\section{Vol.42, No.1. January2023}

at the cell-edge is needed. Multi-band HetNet with threestage internetworking considered in this research is shown in Figure (1). In this multiband HetNet, using LTE Macro $\mathrm{BS}$ and dual-band Wi-Fi (5 GHz), WiGig (60 GHz) small cells, the concepts of sub-clouding are considered. Table (1) shows in detail the specifications of LTE/Wi-Fi/WiGig $5 \mathrm{G}$ Cellular BS used in this paper. A summary of the specification of LTE/Wi-Fi/WiGig is listed in [18] and [19].

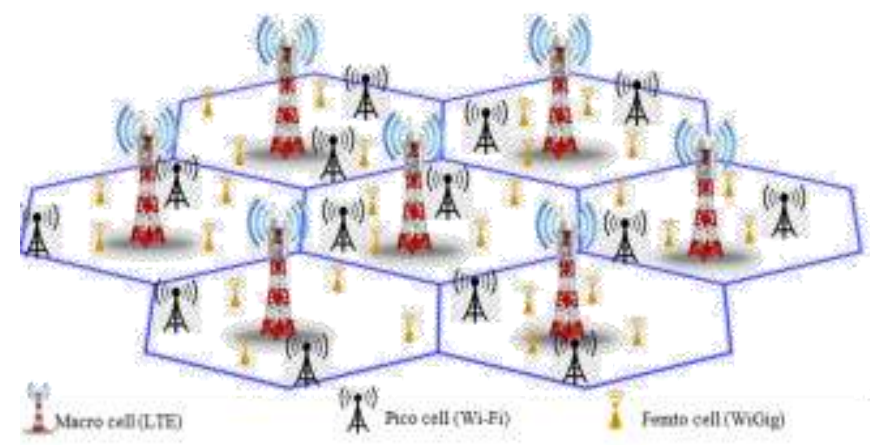

Figure (1): A three-tier Heterogeneous Network structure for the grid model.

Table (1): Specifications of LTE/Wi-Fi/WiGig 5G Cellular system.

\begin{tabular}{|c|c|}
\hline Terms & Value \\
\hline $\begin{array}{c}\text { Transmit power } \\
\text { (LTE, Wi-Fi, mmWave) }\end{array}$ & $\begin{array}{l}46 \mathrm{dBm}, 20 \mathrm{dBm} \\
10 \mathrm{dBm}\end{array}$ \\
\hline $\begin{array}{c}\text { Coverage } \\
\text { (LTE, Wi-Fi, mmWave) }\end{array}$ & $500 \mathrm{~m}, 90 \mathrm{~m}, 10 \mathrm{~m}$ \\
\hline $\begin{array}{c}\text { Antenna height } \\
\text { (LTE, Wi-Fi, mmWave) }\end{array}$ & $25 \mathrm{~m}, 10 \mathrm{~m}, 3 \mathrm{~m}$ \\
\hline LTE carrier, BW, Max rate & $\begin{array}{l}2 \mathrm{GHz}, 20 \mathrm{MHz} \\
100 \mathrm{Mbps}\end{array}$ \\
\hline Wi-Fi carrier, BW, Max rate & $\begin{array}{l}5 \mathrm{GHz}, 40 \mathrm{MHz} \\
600 \mathrm{Mbps}\end{array}$ \\
\hline mmWave carrier, BW, Max rate & $\begin{array}{c}\text { 60GHz, } 2 \mathrm{GHz}, 6.7 \\
\text { Gbps }\end{array}$ \\
\hline No. of Pico cells per Macro cell & $1-20$ \\
\hline $\begin{array}{c}\text { No. of mmWave SCs per Macro } \\
\text { cell pico cell }\end{array}$ & $1-30$ \\
\hline No. of UE per Macro cell & 2000 \\
\hline
\end{tabular}

In classic HetNets, small cell (picocell PBS) and macro base stations use the same frequency bands for band upstream and downstream such that the interference between small and macro cell BSs should be taken in consideration.
Almost every interference allowance technology needs resources segmenting such as splitting of frequencies bands or time slots splitting. While these technologies produce loss of channelization, a superlative between the resources and the interference value will be present. Moreover, Heterogeneous Networks with multi-band frequencies prevent inter-system interference as a result of using distinct spectrum bands for both small BSs and Macrocell BSs. This paper takes into consideration two different types of multiband frequencies in Heterogeneous Networks. The Macrocell uses the $2 \mathrm{GHz}$ frequency band, while the small cell uses the $3.5 \mathrm{GHz} / 60 \mathrm{GHz}$ frequency bands.

\section{THE DISTRIBUTION MODELS}

\subsection{Poisson Point Process (HPPP)}

This model assumes a plain HetNet consisting of a grid hexagonal MBS mobile network. In this scenario, random Pico and Femto BSs are deployed and located inside the macro station. A snapshot for the simulated HPPP mobile network scenario is shown in figure (2). This scenario uses the is symbol for the Macro base station located in the core of the coverage area, the + symbol for the small BSs (pico) which are located surrounding the MBS, and the . symbol for the femtocells which are distributed randomly inside the HetNet.

\subsection{Poisson Cluster Processes (PCP)}

This distribution method comes from homogeneous clustering applied to the homogeneous Poisson Point Process. It is thought that the downlink of a multi-tier Heterogeneous Network consists of a network of MBSs covered by random distributed pico/femtocell BSs. The BSs in each tier may vary in factors of transmitted power, density of cells, and reliability of the UE/BS link. Also, this BS differs in the bias towards admitting mobile users. As shown in figure (3), the cell positions are spread according to PCP [20-21] in which the clustering process is composed of the parent process which forms the cluster center and daughter points that are uniform randomly distributed in a ball of radius, $\mathrm{R}$, around the cluster center using a density function $f(x)$ where

$$
f_{M}(x)=\left\{\begin{array}{cc}
\frac{1}{\pi R^{2}} & \text { if }\|x\| \leq R \\
0 & \leq R
\end{array}\right.
$$

$\mathrm{x}$ denotes the two dimension coordinates proportional to the center of the cluster and $\|\cdot\|$ points to the Euclidean norm.

\subsection{Matern Cluster Processes (MCP)}

In this model, the number of points in the intended cluster is a Poisson distribution where its mean is $\bar{c}$. The intended cluster points are uniformly independent and scattered with the ball of radius $\mathrm{R}$. The model proposed in this work considers a three-tier deployment of the Base Stations. The 


\section{Vol.42, No.1. January2023}

MBSs positions in the first-tier use a homogeneous PPP. The second-tier Pico SBSs position use a Matern cluster process $(\mathrm{MCP})$, whose parent point process is the $1^{\text {st }}$ tier HPPP. The daughter points process is dispersed in the same way on the ball of radius, $R$, with its center at parent points. This method considers that the average number of Small BS in any cluster is $\bar{c}$. In the same way, the third-tier femto Small BSs locations are distributed based on MCP with parent points process using that of the $1^{\text {st }}$ tier HPPP, as shown in figure (4). It is axiomatic that each tier possesses its own special transmission power.

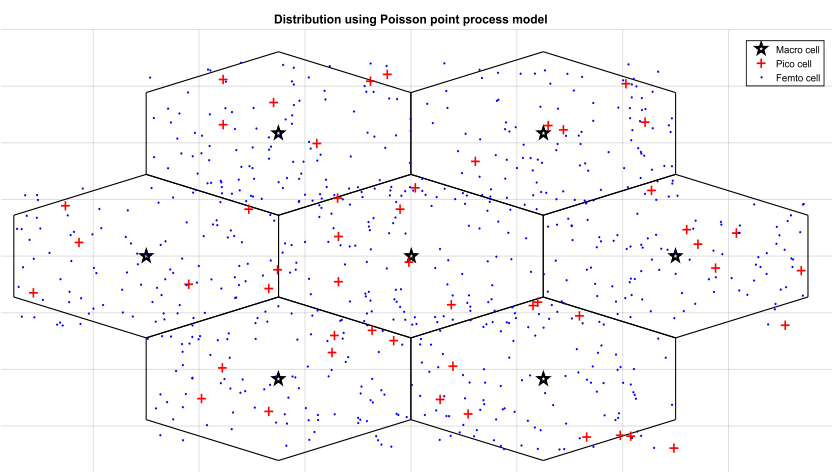

Figure (2): Simulated network scenario using HPPP model

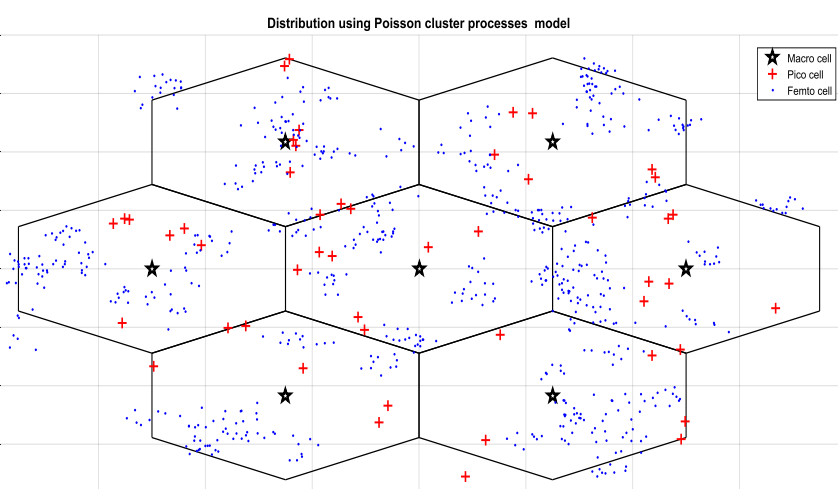

Figure (3): Simulated network scenario using PCP model

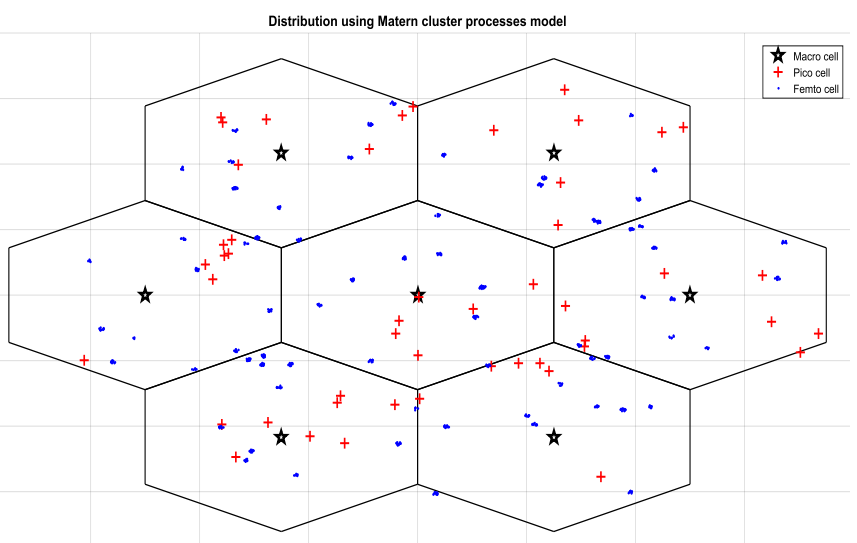

Figure (4): Simulated network scenario using MCP model

\section{ASSOCIATION SYSTEM}

HetNet architecture acts as the main issue in improving the user association performance algorithms. Architecture of the HetNet should be considered as design efficient algorithms for user association. The network architecture affects how the UE traffic is served. For example, the BS which may serve the UE needed traffic via the backhaul connection that traffic would pass till it arrives at the main core network. Due to the presence of many BS in addition to many tiers in the $5 \mathrm{G}$ architecture networks, there must be a highly efficient strategy to connect all the UE with a certain BS. This strategy achieves the highest performance and usage of resources in the network, in addition to achieving the highest utility for UE and BS.

Game theory is considered as one of the greatest and most powerful methods that is able to solve network association problems. It also has different advantages in the realization of the fundamental interaction of many players. Multiple strategies combined to incorporate best strategies for all players are theoretically defined as an equilibrium. The applied game aims are to reach the Nash Equilibrium so that none of the two players is able to raise its own utility by modifying its strategy with no decrease in the utility of the others. The intended players could be the UEs, the base stations, or both of them, while player's strategies arise from the related decisions of the user association. Nash Bargaining Solution is the solution which is proposed in [22], and will be used as the core idea of the proposed work.

Now, suppose the user association matrix is

$$
\mathfrak{x}_{m n}=\left\{\begin{array}{l}
1, \text { if } U E_{n} \text { associated with } B T S_{m} \\
0, \quad \text { Other wise }
\end{array}\right.
$$

This section formulates the user association optimization as a bargaining problem for NBS with all metrics (QoS, fairness, spectrum efficiency, cell load balance, etc.). We can say that a pair of payoffs $\left(v_{1}^{*}, v_{2}^{*}\right)$ is a Nash bargaining solution if it solves the following optimization problem:

$$
\begin{array}{lc}
\max _{v_{1}, v_{2}} & \left(v_{1}-d_{1}\right)\left(v_{2}-d_{2}\right) \\
\text { subject to } & \left(v_{1}, v_{2}\right) \in U \\
& \left(v_{1}, v_{2}\right) \geq\left(d_{1}, d_{2}\right)
\end{array}
$$

The Utility function (payoffs) of each $U E_{n}: v_{m n}=$ $\log \left(r_{m n}\right) / \log \left(r_{n}^{\min }\right)$ where:

$r_{m n}=C_{m n} / \sum_{n=1}^{N} \mathfrak{x}_{\mu n}$ is the data rate from $\mathrm{BTS}(\mathrm{m})$ to $\mathrm{UE}(\mathrm{n})$.

$C_{m n}:$ The UE(n)-BS(m) link capacity

$r_{n}^{\text {min }}$ : Minimum Data Rate needed to UE(n).

$d_{\mathrm{n}}$ : minimum utility (payoffs) of each $U E_{n}$, which mean that the UE reaches the minimum data rate required

The optimized problem based on NBS is formulated as: 


\section{Vol.42, No.1. January2023}

$P=\underset{\left(U_{1} \cdots U_{M}\right)}{\max } \quad \prod_{m=1}^{M} \quad\left(U_{m}-d_{m}\right)$

where:

$U_{m}=\sum_{n=1}^{N} \mathfrak{x}_{m n} \frac{\log C_{m n}-\log \sum_{n=1}^{N} x_{m n}}{\log r_{n}^{\min }}$, is The utility

for each UE associated to the BS.

$d_{m}=\sum_{n=1}^{N} \mathfrak{X}_{m n}$ is the disagreement for all UE connected to the BTS.

All UE are partitioned into a suggested Macro and Picocell to be associated with. So the two players here are the Macro and Pico BTS Cell. For the Macro cell $U_{\mu}$ $U_{\mu}=\sum_{n=1}^{N} \mathfrak{X}_{\mu n} \frac{\log C_{\mu n}-\log \sum_{n=1}^{N} \mathfrak{x}_{\mu n}}{\log r_{n}^{\min }}$ and $d_{\mu}=\sum_{n=1}^{N} \mathfrak{X}_{\mu n}$. For the Picocell $U_{\rho}=\sum_{n=1}^{N} \mathfrak{x}_{\rho n} \frac{\log c_{\rho n}-\log \sum_{n=1}^{N} x_{\mu n}}{\log r_{n}^{\min }}$ and $d_{\rho}=$ $\sum_{n=1}^{N} \mathfrak{X}_{\rho n}$.

Optimization problem is formulated as:

(3)

$$
P\left(\mathfrak{x}_{\mu}, \mathfrak{x}_{\rho}\right)=\max _{\mathfrak{x}^{*}}\left(U_{\mu}-d_{\mu}\right)\left(U_{\rho}-d_{\rho}\right)
$$

$$
\begin{array}{r}
=_{x^{.}}^{\max }\left(\sum_{n=1}^{N} \mathfrak{x}_{\mu n} \frac{\log C_{\mu n}-\log \sum_{n=1}^{N} \mathfrak{x}_{\mu n}}{\log r_{n}^{\min }}-\right. \\
\left.\sum_{n=1}^{N} \mathfrak{X}_{\mu n}\right)\left(\frac{\log C_{\rho n}-\log \sum_{n=1}^{N} \mathfrak{x}_{\mu n}}{\log r_{n}^{\min }}-\sum_{n=1}^{N} \mathfrak{x}_{\rho n}\right)
\end{array}
$$

What is required now is to maximize the optimization problem $P\left(\mathfrak{x}_{\mu}, \mathfrak{x}_{\rho}\right)$ subject to the constraint: $\mathcal{G}\left(\mathfrak{x}_{\mu}, \mathfrak{x}_{\rho}\right)=$ $\mathfrak{X}_{\mu}+\mathfrak{x}_{\rho}=1$. In this problem we will use the Lagrange multiplier facility to solve this problem defined by:

$$
\begin{aligned}
& \mathcal{L}\left(\mathfrak{x}_{\mu}, \mathfrak{x}_{\rho}, \lambda\right)=P\left(\mathfrak{x}_{\mu}, \mathfrak{x}_{\rho}\right)+\lambda\left(\mathcal{g}\left(\mathfrak{x}_{\mu}, \mathfrak{x}_{\rho}\right)-1\right) \\
& \quad=\left(U_{\mu}-d_{\mu}\right)\left(U_{\rho}-d_{\rho}\right)+\sum_{n=1}^{N} \lambda_{n}\left(\mathfrak{x}_{\mu}+\mathfrak{x}_{\rho}-1\right)
\end{aligned}
$$

The next step is to solve the gradient of the $\mathcal{L}\left(\mathfrak{X}_{\mu}, \mathfrak{x}_{\rho}, \lambda\right)$ function. So, $\nabla_{x_{\mu}, x_{\rho}, \lambda} \mathcal{L}\left(\mathfrak{x}_{\mu}, \mathfrak{x}_{\rho}, \lambda\right)=\left(\frac{\partial \mathcal{L}}{\partial x_{\mu}}, \frac{\partial \mathcal{L}}{\partial x_{\rho}}, \frac{\partial \mathcal{L}}{\partial \lambda}\right)=0$

$$
\begin{aligned}
& \frac{\partial \mathcal{L}}{\partial x_{\mu}}=\left(\frac{\partial U_{\mu}}{\partial x_{\mu}}-\frac{\partial d_{\mu}}{\partial x_{\mu}}\right)\left(U_{\rho}-d_{\rho}\right)+\sum_{n=1}^{N} \lambda_{n}=0 \\
& \Rightarrow \sum_{n=1}^{N} \frac{\partial}{\partial x_{\mu}} \mathfrak{X}_{\mu n}\left(\frac{\log C_{\mu n}-\log \sum_{n=1}^{N} \mathfrak{x}_{\mu n}}{\log r_{n}^{\min }}-1\right)\left(U_{\rho}-d_{\rho}\right)+ \\
& \sum_{n=1}^{N} \lambda_{n}=0 \\
& \Rightarrow \sum_{n=1}^{N}\left(\frac{\log C_{\mu n}-\log \sum_{n=1}^{N} x_{\mu n}}{\log r_{n}^{\min }}-1-\frac{x_{\mu n} N}{\log r_{n}^{\min } \sum_{n=1}^{N} x_{\mu n}}\right)\left(U_{\rho}-\right. \\
& \left.d_{\rho}\right)+\sum_{n=1}^{N} \lambda_{n}=0 \\
& \Rightarrow\left(N \frac{\log C_{\mu n}-\log \sum_{n=1}^{N} x_{\mu n}}{\log r_{n}^{\min }}-\frac{N}{\log r_{n}^{\min }}-N\right)\left(U_{\rho}-d_{\rho}\right)+ \\
& \sum_{n=1}^{N} \lambda_{n}=0 \\
& \Rightarrow \frac{N}{\log r_{n}^{\min }}\left(\log \left(C_{\mu n}\right)-\log \sum_{n=1}^{N} \mathfrak{x}_{\mu n}-1-\right. \\
& \left.\log r_{n}^{\min }\right)\left(U_{\rho}-d_{\rho}\right)+\sum_{n=1}^{N} \lambda_{n}=0
\end{aligned}
$$

$$
\begin{aligned}
& \Rightarrow \frac{N}{\log r_{n}^{\min }}\left(\log \left(r_{\mu n}\right)-1-\log r_{n}^{\min }\right)\left(U_{\rho}-d_{\rho}\right)+ \\
& \quad \sum_{n=1}^{N} \lambda_{n}=0 \\
& \frac{\partial \mathcal{L}}{\partial x_{\rho}}=\left(\frac{\partial U_{\rho}}{\partial x_{\rho}}-\frac{\partial d_{\rho}}{\partial x_{\rho}}\right)\left(U_{\mu}-d_{\mu}\right)+\sum_{n=1}^{N} \lambda_{n}=0 \\
& \Rightarrow \frac{N}{\log r_{n}^{\min }}\left(\log \left(r_{\rho n}\right)-1-\log r_{n}^{\min }\right)\left(U_{\mu}-d_{\mu}\right)+ \\
& \quad \sum_{n=1}^{N} \lambda_{n}=0 \\
& \text { Let: } g_{\mu}=1 /\left(U_{\mu}-d_{\mu}\right), g_{\rho}=1 /\left(U_{\rho}-d_{\rho}\right), \text { and then }
\end{aligned}
$$

subtract eq. (13) from eq. (11) then:

$$
\begin{aligned}
& \Rightarrow \frac{\log \left(\frac{c_{\mu n}}{r_{n}^{\min }}\right)-1}{U_{\mu}-d_{\mu}}=\frac{\log \left(\frac{c_{\rho n}}{r_{n}^{\min }}\right)-1}{U_{\rho}-d_{\rho}} \\
& \Rightarrow \log \left(\frac{c_{\mu n}}{r_{n}^{\min }}\right)^{g_{1}}-g_{1}=\log \left(\frac{c_{\rho n}}{r_{n}^{\min }}\right)^{g_{2}}-g_{2}
\end{aligned}
$$

In equation (15), when the left side is greater than the value of the other side, it gives the highest utility of the system if $U E_{n}$ is associated to Macrocell and conversely for Picocell (as an example). In case of many BSs, most of the traditional researches in the literature concentrate on solving the dilemma of user association inside multiple BSs together in a centralized method. While this problem is combinatorial in itself, the centralized technique will afford a very high complex computation with $\mathrm{O}\left(M^{N}\right)$ (where $\mathrm{M}, \mathrm{N}$ are the numbers of Base Stations and users, respectively). Computation like this is impossible even for medium or small sized cellular wireless network.

This paper uses the cell-based association algorithm proposed algorithm in [23]. In this algorithm, all UE is associated with BS that achieves max Link Capacity for each UE. Then a Ranking Table is established. This table contains the first BSs that give the highest utility for each UE. By an iterative method, the algorithm finds the appropriate BS for each UE that achieves maximum utility for the total system based on equation (3). Also, the complexity of computation could be greatly reduced as well as the algorithm which has the ability to make the association, based on the type of data usage (streaming, chat, etc.) by modifying the utility equation.

\section{EXPERIMENTS AND RESULTS}

The experiments assume a plain HetNet consisting of a grid hexagonal MBS mobile network. In this simulation, Pico and Femto BSs are deployed and located inside the macro station, in a random manner based on the distribution model used. Table (1) shows in detail the specifications of LTE/Wi-Fi/WiGig 5G Cellular BS for the 5G network user association. Many terms are adopted to determine which base station would serve the intended UE. Many metric terms are generally used in this study such as outage/coverage probability, energy efficiency, fairness, and QoS. This section explores the proposed NBS association 


\section{Vol.42, No.1. January2023}

technique performance in [23] to compare between the different distribution techniques.

The following experiments discuss the proposed system performance from the point of view of optimality, complexity, power consumed, optimal network operation, and mobility. Fairness demands and percentage of UE that reached the needed traffic is discussed versus the processing time issue. Users in heterogeneous networks are usually not distributed in a uniform matter. Studying the impact of not uniformly distributed users on Heterogeneous network performance is necessary to design an efficient cellular mobile network. In this work, a not uniformed distribution model for UE of the user positions depends on the distance till the associated cell is used [24]. Figure (5), shows a snapshot of the UE location.

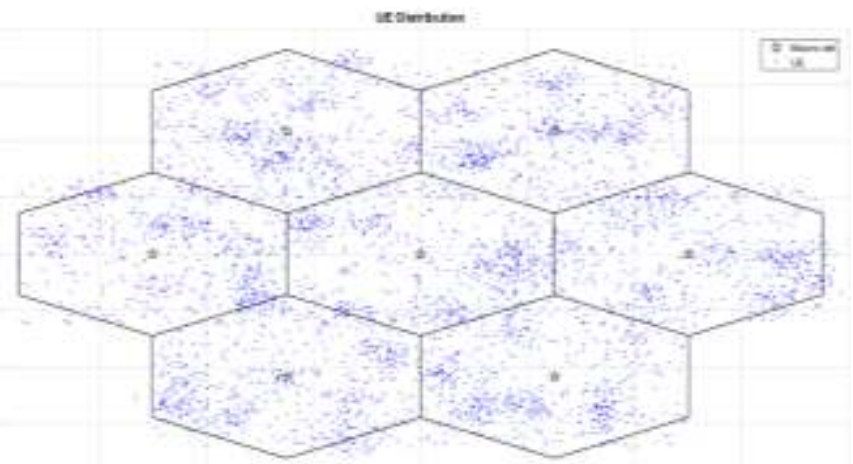

Figure (5): UE distribution in Simulated network

\subsection{Experiment 1}

The first experiment discusses the performance of the applied CPA algorithm [22], with the HPPP, PCP, and MCP distribution models. This experiment illustrates the improvement in total system data rate (SDR) and the Jain's Fairness Index (JFI) with the total UE number used in the three distribution models. Figure (6) shows the users total system data rate (SDR) against different UEs number in the HetNets area. The essential variation between PPP and PCP distribution models is that the total data outage of PPP doesn't depend on the density of spatial area, while the total data outage of PCP is closely affected by spatial density. From an in-depth examination of the results obtained from this experiment, it is clear that using the Matern Cluster Point process as a distribution model gives the highest results from the viewpoint of total system data rate (SDR). Figure (7) demonstrates the effect of the distribution model on the JFI. It turns out that the proposed distribution of PCP for small cells gives a resultant flat curve with JFI which means that this proposal deals fairly with changing the number of users in the cellular network. Figure (7) also shows that the JFI affected in a negative way with the increment of the cellular network number users when using other distribution models PPP and PCP for small cells. Also it clear that the MCP distribution model achieve the highest DR throughput by $14 \%$ increase compared with HPPP and PCP and achieve the best JFI by $8 \%$ increasecompared with HPPP and PCP.

\subsection{Experiment 2}

This experiment has effectively exposed the impact of the increment of the total number of users in cellular networks on the percentage of UEs associated with different HetNet tiers. Figure (8) indicates the percentage of UEs associated with the small BS (Picocell and Femtocell) in the presence of a different number in the macro cell. Also, this experiment shows the difference between the distribution models of distributing SBS cells and the effect of each model on the percentage of UEs associated with small cells. Figure (8) shows that the use of PPP and MCP as a distribution model gives better results than using PCP from the point of view of the percentage of UEs associated with small cells.

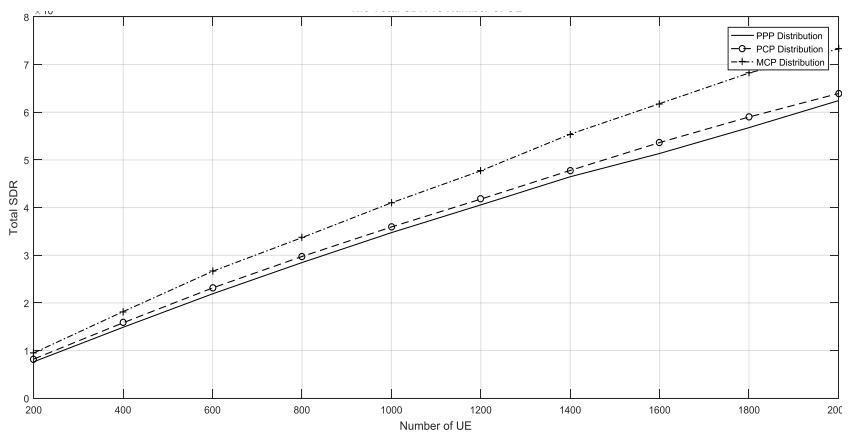

Figure (6): Total data rate versus various total UEs number.

\subsection{Experiment 3}

The last experiment in this paper review in detail the effect of the small cell distribution model on the percentage of users whose data flow requirements are met. Figure (9) show the results of this experiment which shows the clear difference between the three models used to locate small cells in the HetNet. It is viewed that the MCP distribution model achieves the highest percentage of users that could take its data rates demands while the Poisson Point Process and Poisson Cluster Process give almost the same results.

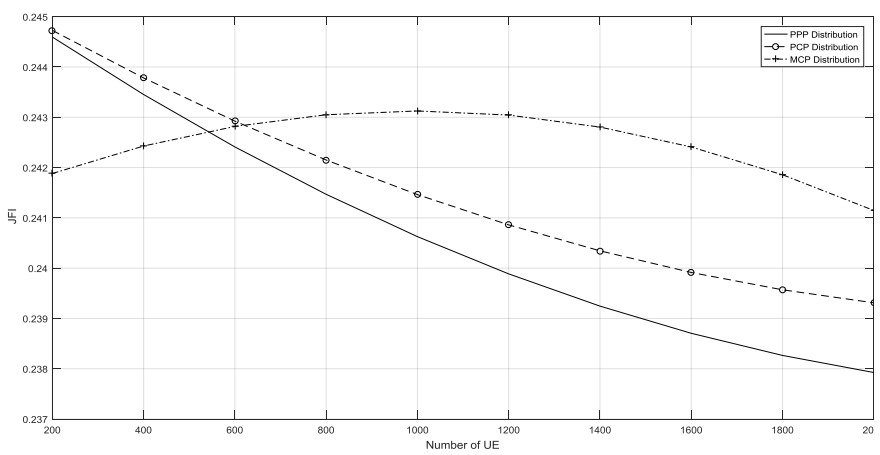

Figure (7): The Jain's Fairness Index versus the total UEs number 


\section{Vol.42, No.1. January2023}

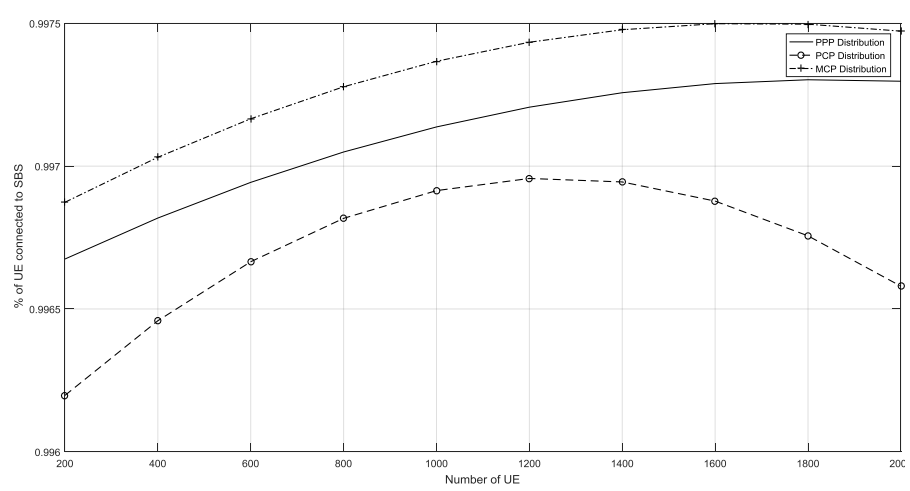

Figure (8): Percentage of UE in each SBS tiers versus total UE number

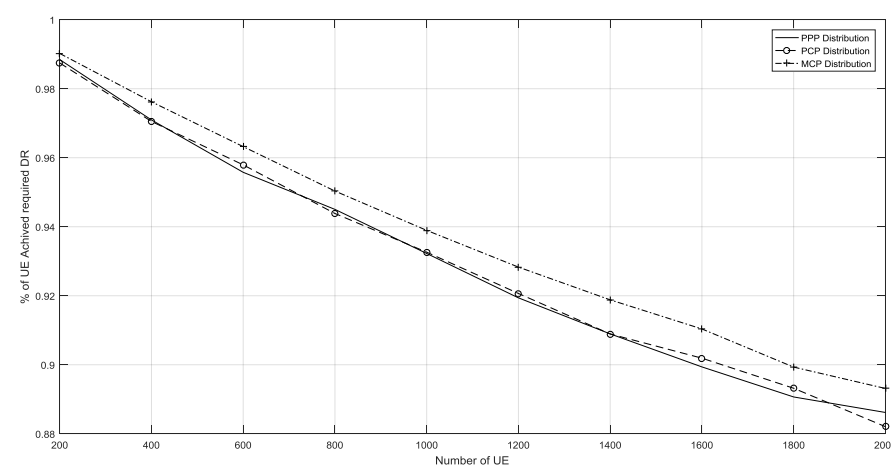

Figure (9): Percentage of UE that achieved required traffic versus total UE number

Finally, it appears to a large extent that the use of the Matern Cluster Process as a model for small cell distribution in the cellular network gives the best system performance results. The MCP distribution model has the advantage of taking the MBS/SBS dependence into consideration. Another advantage in MCP is that the data rate depends on the spatial density and closely affected by it, as is the case in PCP, while this property not considered the PPP distribution model.

\section{CONCLUSION}

This paper discusses the effect of distribution models on the association system performance. In this study, we considered the homogeneous Poisson Point Process (HPPP), Poisson Cluster Processes (PCP), and Matern Cluster processes (MCP) as distribution models. This research used the Cell Based Association algorithm (CBA) which is based on the Nash Bargaining Solution. It works on a 3-tier heterogeneous network with the perspective of a newly emerging WiGig technology. This research faces a challenge which is the usage of the non-uniform user distribution model in which the user density depends on the distance to the associated base stations. The main feature in the PCP approach is that the obtained results are in agreement with [1] and [13] and this leads to a complementary theoretical tool for the interference model over an urbanized and rustic area regardless of whether the UEs and BSs are clustered or not. Although the PCP model considers a clustering property of Small BSs, it doesn't take into consideration the MBSs/SBSs dependence. In terms of future work and extending the present research, we plan to study the effect of the association algorithm on system performance. One of the most useful features is to use the results obtained in this study to suggest a model to distribute cells in the cell association of cognitive radio systems.

\section{REFERENCES}

[1] H. S. Dhillon, R. K. Ganti, F. Baccelli, and J. G. Andrews, "Modeling and analysis of K-tier downlink heterogeneous cellular networks," IEEE Journal on Selected Areas in Communications, vol. 30, pp. 550-560, 2012.

[2] D. Liu, L. Wang, Y. Chen, M. Elkashlan, K.-K. Wong, R. Schober, et al., "User association in 5G networks: A survey and an outlook," IEEE Communications Surveys \& Tutorials, vol. 18, pp. 1018-1044, 2016.

[3] Q. Cui, T. Yuan, and W. Ni, "Energy-efficient two-way relaying under non-ideal power amplifiers," IEEE Transactions on Vehicular Technology, vol. 66, pp. 12571270, 2016.

[4] Q. Cui, H. Song, H. Wang, M. Valkama, and A. A. Dowhuszko, "Capacity analysis of joint transmission CoMP with adaptive modulation," IEEE Transactions on Vehicular Technology, vol. 66, pp. 1876-1881, 2016.

[5] 3GPP TR 36.912 V2.0.0, "3rd Generation Partnership Project; Technical Specification Group Radio Access Network; Feasibility study for Further Advancements for E-UTRA (LTE-Advanced) (Release 9)”, Aug 2009.

[6] N. Docomo, "Performance of eICIC with control channel coverage limitation," R1-103264, 3GPP Std., Montreal, Canada, vol. 5, p. 27, 2010.

[7] A. Khandekar, N. Bhushan, J. Tingfang, and V. Vanghi, "LTE-advanced: Heterogeneous networks," in 2010 European wireless conference (EW), 2010, pp. 978982 .

[8] H. Shimodaira, G. K. Tran, K. Araki, S. Nanba, T. Hayashi, K. Sakaguchi, et al., "Cell association method for multiband heterogeneous networks," in 2014 IEEE 25th Annual International Symposium on Personal, Indoor, and Mobile Radio Communication (PIMRC), 2014, pp. 22092213.

[9] A. Khandekar, N. Bhushan, J. Tingfang, and V. Vanghi, "LTE-advanced: Heterogeneous networks," in 2010 European wireless conference (EW), 2010, pp. 978 982. 


\section{Vol.42, No.1. January2023}

[10] T. Qu, D. Xiao, and D. Yang, "A novel cell selection method in heterogeneous LTE-advanced systems," in 2010 3rd IEEE International Conference on Broadband Network and Multimedia Technology (IC-BNMT), 2010, pp. 510513.

[11] R. Trestian, O. Ormond, and G.-M. Muntean, "Game theory-based network selection: Solutions and challenges," IEEE Communications surveys \& tutorials, vol. 14, pp. 1212-1231, 2012.

[12] H. ElSawy, E. Hossain, and M. Haenggi, "Stochastic geometry for modeling, analysis, and design of multi-tier and cognitive cellular wireless networks: A survey," IEEE Communications Surveys \& Tutorials, vol. 15, pp. 9961019, 2013.

[13] H.-S. Jo, Y. J. Sang, P. Xia, and J. G. Andrews, "Heterogeneous cellular networks with flexible cell association: A comprehensive downlink SINR analysis," IEEE Transactions on Wireless Communications, vol. 11, pp. 3484-3495, 2012.

[14] Y. J. Chun and M. O. Hasna, "Analysis of heterogeneous cellular networks interference with biased cell association using Poisson cluster processes," in 2014 International conference on information and communication technology convergence (ICTC), 2014, pp. 319-324.

[15] Y. J. Chun, M. O. Hasna, and A. Ghrayeb, "Modeling heterogeneous cellular networks interference using poisson cluster processes," IEEE Journal on Selected Areas in Communications, vol. 33, pp. 2182-2195, 2015.

[16] Y. Xie, X. Zhang, Q. Cui, and Y. Lu, "User association for offloading in heterogeneous network based on matern cluster process," in 2017 IEEE 85th Vehicular Technology Conference (VTC Spring), 2017, pp. 1-5.

[17] N. Deng, W. Zhou, and M. Haenggi, "Heterogeneous cellular network models with dependence," IEEE Journal on selected Areas in Communications, vol. 33, pp. 2167$2181,2015$.

[18] I. Selinis, K. Katsaros, M. Allayioti, S. Vahid, and R. Tafazolli, "The race to $5 \mathrm{G}$ era; LTE and Wi-Fi," IEEE Access, vol. 6, pp. 56598-56636, 2018.

[19] G. Naik, J.-M. Park, J. Ashdown, and W. Lehr,
"Next generation Wi-Fi and 5G NR-U in the $6 \mathrm{GHz}$ bands: Opportunities and challenges," IEEE Access, vol. 8, pp. 153027-153056, 2020.

[20] S. N. Chiu, D. Stoyan, W. S. Kendall, and J. Mecke, Stochastic geometry and its applications: John Wiley \& Sons, 2013.

[21] R. K. Ganti and M. Haenggi, "Interference and outage in clustered wireless ad hoc networks," IEEE Transactions on Information Theory, vol. 55, pp. 4067-4086, 2009.

[22] A. Zakaria and A. I. Hussein, "Optimal users association of LTE Wi-Fi Wi-Gig bands in 5G Cellular Networks," International Journal on Semantic Web and Information Systems (IJSWIS), vol. 17, pp. 17-32, 2021.

[23] A. Zakaria and A. I. Hussein, "Cell Association for Multi Band 5G Cellular HetNets based on NBS," in 2018 30th International Conference on Microelectronics (ICM), 2018, pp. 28-31.

[24] C. Li, A. Yongacoglu, and C. D'Amours, "Heterogeneous cellular network user distribution model," in 2016 8th IEEE Latin-American Conference on Communications (LATINCOM), 2016, pp. 1-6.

[[25] C. Saha, H. Dhillon, N. Miyoshi and J. Andrews, "Unified Analysis of HetNets Using Poisson Cluster Processes Under Max-Power Association", IEEE Transactions on Wireless Communications, vol. 18, no. 8, pp. 3797-3812, 2019.

[26] M. Afshang and H. Dhillon, "Poisson Cluster Process Based Analysis of HetNets With Correlated User and Base Station Locations", IEEE Transactions on Wireless Communications, vol. 17, no. 4, pp. 2417-2431, 2018. Available: 10.1109/twc.2018.2794983.

[27] W. Dghais, M. Souilem, H. Chi, A. Radwan and A. Taha, "Dynamic Clustering for Power Effective Small Cell Deployment in HetNet 5G Networks", ICC 2020 - 2020 IEEE International Conference on Communications (ICC), 2020 . 


\section{Vol.42, No.1. January2023}

\section{الملخص}

استخدام شبكات الجيل الخامس $5 \mathrm{G}$ الهجينه لمحطات الخلايا الصغيره ذات القدره الكهربيه المنخفضه وقليله التكلفه يعبر حلا قيما لتحسين قدره محطات

الخلايا الكبيره من خيث الموثوقيه و التغطيه و السر عات المطلوبه إلخ. مع ذلك فإن انتشار محطات الخلايا الضغير ومتناهيه الصغر يو اجه مشاكل وتديات مثل اداره التداخل و عدم كفايه الاطر المرنه لمحطات الخلايا الصغيره. يتضخم هذا التحدي في ظل وجود مو اقع عشو ائيه للمستخدمين واحتياجاتهم. نماذج محاكاه مو اقع محطات الخلايا الصغيره باستخدام الهندسه العشو ائيه لتحديد كفاءة الاتصال خلال شبكات لاسلكيه عشو ائيه اصبح له احتياج كبير . يدرس هذا البحث تأثثر توزيع مو اقع محطات الخلايا الصغيره على الأداء العام للشبكة الخلوية. تعتبر طريقة نقطه بواسون PCP الغير المتجانسه و عمليه تكتل بو اسون PCP ومليه تكتل ماتيرن MCP بمثابة نماذج توزيع مستخدمة لهذه الدر اسة. خوارزمية التر ابط الخلوي المستخدمة في هذا البحث هي خوارزمية الر ابطة القائمة على الخلية (CBA) و التي تعتمد على حل ناش للمساو مة NASH BARGAINING SOLUTION التحديات التي تم تناولها في هذه الورقة هي عمل ارتباط الخلية في شبكات غير متجانسة في ثلاثة مستويات مع منظور تقتية مIGG الناشئة حديثًا. التحدي الآخر الذي تم تناوله في هذه الورقة هو الاخذ في الاعتبار طريقة توزيع المستخدمين داخل الثبكه. تفترض هذه الورقة أن المستخدم موزع على أساس نموذج التوزيع غير المنتظم للمستخدم الذي تعنمد فيه كثافة المستخدم على المسافة إلى المحطات الأساسية المرتبطة يحقق نموذج نوزيع

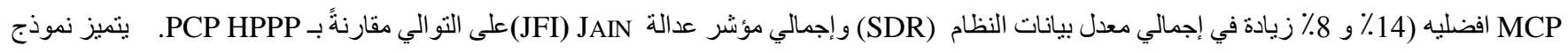

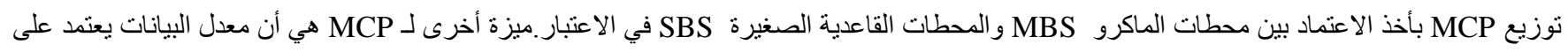
كثافة المنطقة الجغر افيه ويتأثر بها يشكل كبير ، كما هو الحال في PCP ، في حين أن هذه الخاصية غير معتبره في نموذج توزيع PPP. الكلمات المفتاحيه : الجيل الخامس، شبكات الاتصالات الهجينه، طريقة نقطه بو اسون PPP و عمليه تكتر ماتيرن PCP الغير المتجانسه و عمليه تكتل بو اسون MCP 